\title{
The Digital Disruption and its Societal Impacts
}

\author{
Martin Kenney • Petri Rouvinen • John Zysman
}

Received: 21 November 2014 / Revised: 30 November 2014 /

Accepted: 3 December 2014 / Published online: 10 February 2015

(C) The Author(s) 2015. This article is published with open access at Springerlink.com

\begin{abstract}
Deepening digitalization and globalization has induced an ongoing societal transformation that may ultimately prove to be as significant as the original industrial revolution. Even as the ICT industry is being restructured, global competition is being transformed. Previously dominant firms - including telecommunications carriers, equipment providers, and powerful legacy software firms - are under assault from the move to cloud computing, in the network center, and mobile computing, on the network periphery. This transformation of the computing and communication infrastructure has been occurring simultaneously with the spread of ever more complicated and sophisticated global value chains. The articles in this special issue explore a number of the key facets of this transformation in a comparative lens. The authors find that the social, legal, and economic arrangements will impact how these changes affect nation-states. For policy-makers there will be serious dilemmas, as they will have to simultaneously nurture and support many aspects of these changes, while also mitigating or channeling some of the outcomes so as to protect privacy, income equality, and fair taxation.
\end{abstract}

Keywords ICT Structural change Convergence $\cdot$ Commoditization $\cdot$ Political economy

JEL Classification $\mathrm{L} 14 \cdot \mathrm{O} 33 \cdot \mathrm{P} 11$

\section{Introduction}

This special issue studies the "nuts and bolts" of the globally ongoing societal transformation induced by recent advances in digital technologies and deepening globalization. The lingering

\footnotetext{
M. Kenney

Community and Regional Development Unit, University of California, Davis, CA 95616, USA

e-mail: mfkenney@ucdavis.edu

P. Rouvinen $(\bowtie)$

ETLA, The Research Institute of the Finnish Economy, Lönnrotinkatu 4 B, 00120 Helsinki, Finland e-mail: petri.rouvinen@etla.fi

\section{J. Zysman}

Berkeley Roundtable on the International Economy (BRIE), University of California Berkeley, 2234

Piedmont Ave, Berkeley, CA 94720, USA

e-mail: zysman@berkeley.edu
} 
economic crisis has somewhat hidden the fact that we are heading to some new-yet to be appropriately named - economic era. And while the crisis has largely taken our collective attention elsewhere, overall it is probably accelerating the ongoing transition.

The long discussed digital convergence has finally occurred in a major way and early competitive positions in the post-convergence digital agglomeration have been established. The information and communication technology (ICT) industry has been, and will be, significantly restructured. The benefits of this merger are many. And yet, for previous industry leaders, and sometimes for national economies hosting them, the change has been most unpleasant. Japan and Europe have been mighty in certain ICT sectors in the 1990s and in the early 2000s; for the current ICT revolution, the key new aspects-discussed in detail in this special issue - are emerging from Silicon Valley and the US.

\section{Contributions in this Special Issue}

Kushida et al. (2014) discuss how cloud computing is inducing a fundamental paradigm shift, as computing is transformed from a scarce to an abundant resource. The advent of cloud platform services and global cloud service providers have challenged several previously dominant business models in the ICT sector by commoditizing previously high value added activities, while also enabling a vast array of new potential activities. Abundant, ubiquitous, and cheap ICT resources have the potential to alter competitive dynamics in most industries also outside the core sectors; in fact any information intensive process - from social services to surveillance-is experiencing a major change. The authors urge focus on political and regulatory ramifications of cloud computing. Discussions on antirust, privacy, and security have been opened but remain at their early stages. Cloud computing makes it inherently difficult to define relevant jurisdiction, liabilities of various parties involved, and the appropriate scope of industrial promotion policies - while all of these have been touched upon in a variety of national and regional contexts, the underlying issues are far from being resolved.

Pon et al. (2014) study powerful mobile technology platforms that Apple, Google, Microsoft, and others have built around smartphone operating systems. Even though the starting point of the analysis is the smartphone industry-echoing the previous article by Kushida et al. (2014) - the authors find that battleground of competition is shifting away from the devices and their operating systems to Internet-based cloud platforms. Users ultimately desire email, social media access, online calendars, streaming media, file storage, video conferencing, real-time collaboration, and other services from all of their devicessmartphones, tablets, and PCs-, all of which are capable of allowing access. What the smartphone catalyzed is a change in the location of the lock-in for the providers and the bottleneck from the users' point of view. The new lock-in is no longer the device but rather the cloud-based services they access. The cloud center(s) is becoming the meta-platform that subsumes all of the devices. The authors borrow from the Lord of the Rings in suggesting that the cloud may become "the one ring to bind and unite them all" that takes the long-discussed convergence of various ICT sub-sectors to completion.

Huberty (2014) focuses on what resides in the cloud, big data-large volumes of rapidly accumulating data of various kinds that registers information about individuals' behavior online. He suggests that big data is in its infancy and in order for it to live up to its commercial promise, certain shortcomings have to be first acknowledged and then addressed. He defines and challenges four previously unstated assumptions underlying big data: (1) all the individuals one cares about are included in the data, (2) one is able to identify the individuals of interest, (3) online behavior is consistent with offline behavior, and (4) individuals' 
representation of themselves are consistent over time. Strictly speaking, none of these four assumptions is true. Huberty defines three orders of viable big data business models. The first two of these are already well-known: the third-order business model is in essence online advertising; the second-order business model is online retailing. Huberty argues that the real changes will come from the first-order business models that are deeply embedded in, and reliant upon, data generated from and around real-world phenomena. Here, he cites products such as Nest thermostats that utilize direct home appliance data to make valuable decisions or the Google Translate function that provides a big data service directly. He believes that these types of applications are where the true value of big data can be realized.

Kushida (2014) concentrates on the politics of ICT commoditization, i.e., he argues that national-level political and socio-economical dynamics influenced the rapid disruptions experienced by global ICT industries. His analysis suggests that local regulatory and technology choices played critical roles in shaping globally disruptive business models driving commoditization. Thus, global industry disruptions are shaped by a set of local political bargains particularly in the early stages of technological trajectories. In the context of mobile telecommunications, operators won the early political fights in Japan and equipment manufacturers in Europe, but eventually US-based computing-centric leaders emerged and ultimately commoditized all other players, both domestically and internationally. Even though - in the context of ICT - technological opportunities have been largely symmetric and we are often compelled to study variations in business strategies in an effort to explain competitive outcomes, Kushida's observations suggest that the underlying trajectories of global competition were shaped by national political dynamics.

Ali-Yrkkö and Rouvinen (2014) study ICT-enabled global value chains (GVCs). Overall, they suggest that value added is less tied to tangible aspects of GVCs than conventional wisdom suggests; typically most value added is attributable to services and intellectual property, which, in part, is attributable to deepening digitalization. The authors challenge much of the previous GVC literature, which concentrated on highend electronics. For example, they study several cases in which the same product is assembled by the same company in two locations, in Finland and abroad - most often in China. As they compare Finnish value added with local versus offshored final assembly, they find that the outcomes vary with the characteristics of the product: Finnish value added is only two percentage points lower for a high-end smartphone (local vs offshored assembly), while it is ten percentage points lower for a low-end feature phone, and nearly 30 percentage points lower, on average, for all machinery and metal products. They suggest that the complexity and heterogeneity of GVCs is under appreciated in prior literature. Furthermore, the commonly held belief that offshoring is ubiquitous may exaggerate its importance, as they find that value chains for basic products and services are not nearly as global as those of advanced products.

\section{Conclusions}

While the articles in this issue touch upon cloud computing, mobile communications, big data, and ICT-induced industrial developments from various angles, one should note that all of them explicitly recognize the emergence of an underlying digital fabric for economic activity (which in turn is almost inseparable from certain aspects of globalization). Internet-and cloud computing as one of its architectural cornerstones - is becoming the "mother platform", which enables or is transforming nearly every aspect of economic activity, as can be seen by the current interest in the emerging internet of things. 
Despite the basic technological building blocks being largely the same worldwide, national and regional incarnations in ICT provision and use will vary. Policies and politics will influence these outcomes in a myriad of complex ways.

ICT and GVC developments are threatening many developed countries with being caught in a "commodity trap", within which their products and services are no longer able to command their previous premium prices due to competition from lower cost providers. As the developing countries have rapidly improved their capabilities and, in the case of some, such as China, become important markets in their own right, the previous leaders are desperately searching ways of escaping the commodity trap. The solution is easy enough to state: in order for a country to remain prosperous, it needs to create distinctive high value added products and services as well as secure lucrative positions in global value chains providing them - but how? The articles in this special issue suggest that value increasingly resides in the systemic level, which translates to the creation and control of relevant platforms and brands associated with them.

With recent major changes with respect to both digitalization and globalization, policymakers find themselves in a double bind. First, they have hard time separating facts from noise, i.e., just comprehending the ongoing developments. Second, these transformations need to be simultaneously nurtured, supported, and protected against. Tools that can be used include infrastructure provision, strategic approaches to standards, and advanced public procurement. Cloud-based new business models - such as AirBnB and Uber-challenge existing institutional arrangements from within, even as the increasingly ubiquitous GVCs make it harder to establish national labor unions. Proactive policy debates require new ways of talking about societal objectives, economic value creation, and, possibly, even what actually constitutes work.

Acknowledgments This research is a part of the ongoing collaboration of BRIE, the Berkeley Roundtable on the International Economy at the University of California at Berkeley, and ETLA, the Research Institute of the Finnish Economy.

Open Access This article is distributed under the terms of the Creative Commons Attribution License which permits any use, distribution, and reproduction in any medium, provided the original author(s) and the source are credited.

\section{References}

Ali-Yrkkö J, Rouvinen P (2014) Slicing up global value chains: a micro view. J Ind Compet Trade. forthcoming Huberty M (2014) Awaiting the second big data revolution: from digital noise to value creation. J Ind Compet Trade. forthcoming

Kushida KE (2014) The politics of commoditization in global ICT industries: a political economy explanation of the rise of Apple, Google, and industry disruptors. J Ind Compet Trade. forthcoming

Kushida KE, Murray J, Zysman J (2014) Cloud computing: from scarcity to abundance. J Ind Compet Trade. forthcoming

Pon B, Seppälä T, Kenney M (2014) One ring to unite them all: convergence, the smartphone, and the cloud. J Ind Compet Trade. forthcoming 